\title{
Is Internal CSR really less Impactful in Individualist and Masculine Cultures?
}

\section{A Multilevel Approach}

\begin{abstract}
Purpose - Drawing on signaling theory and adopting a multilevel approach, this study investigates how meso organizational attributes interact with the cultural setting to affect employees behavioral responses to internal CSR initiatives. This study unpacks the behavioral process through which internal CSR affects employees' organizational citizenship behavior (OCB) in an organization that has obtained SA8000 and that operates in an understudied Italian context characterized by high individualism and masculinity.
\end{abstract}

Methodology - Bootstrapped multi-mediation analysis was used on a sample of 300 employees operating in one of the most important and largest Italian retail stores active in the food industry and involved in socio-environmental responsibility.

Findings - Results show that when a company obtains an internal CSR quality credential, particularly SA8000, an auditable certification standard that signals that a company goes beyond compliance standards to tailor to the well-being of its employees, it will likely attract like-minded employees that will positively react to internal CSR initiatives even when operating in a highly individualistic and masculine culture such as Italy.

Originality - While prior research has shown that internal CSR initiatives have a lower and, in some cases, an insignificant impact on employees' behavioral outcomes in cultures characterized by individualism and masculinity, this study shows that the interaction between the cultural setting and company specific attributes can turn this effect to be significant, strong, and positive.

Keywords: Bootstrapping; Internal corporate social responsibility; Employee behavioral outcomes; Multilevel approach; National culture. 


\section{Introduction}

The ability of companies to meet the ethical and social expectations of their stakeholders has progressively become a necessary and strategic asset to develop positive ethical identities and to strengthen stakeholders' identification, trust, and pride from affiliation with socially responsible organizations (Bouraoui et al., 2018; Brammer et al., 2007; De Roeck et al., 2016; Jamali et al., 2019). Indeed, research has validated the assumption that employees react positively to internal corporate social responsibility (CSR) initiatives by increasing their affective commitment (Farooq et al., 2014; Hofman \& Newman, 2014; Kim et al., 2016), increasing knowledge in the workplace (Farooq et al., 2014), increasing CSR communications to consumers (Edinger-Schons et al., 2018), and decreasing turnover intentions (Kim et al., 2016). Furthermore, these positive effects are stronger when employees operate under humble leadership (Wang et al., 2019).

This growing body of research has resulted in the development of integrative frameworks for understanding various underlying psychological mechanisms that mediate individual reactions to internal CSR (Farooq et al., 2014, 2016; Gond et al., 2017; Shen \& Benson, 2016). In this context, recent research shows that macro cultural factors are likely to affect how employees respond to internal CSR, emphasizing that in cultures characterized by individualism and masculinity internal CSR initiatives will have less and, in some cases, no impact on the behavioral responses of employees (Farooq et al., 2014; Hofman \& Newman, 2014; Mueller et al., 2012). However, less is known about how company specific attributes interact with macro cultural variables to affect employees' reaction to internal CSR. This is unfortunate given the growing calls for multilevel research to truly understand employees' behavioral responses to internal CSR activities of companies (Gond et al., 2017; Shen \& Benson, 2016).

In this paper, we contribute to this line of research by unpacking the behavioral process through which internal CSR affects employees' organizational citizenship behavior (OCB) in an interesting organizational setting, namely a company operating in Italy that was among the first to have obtained SA8000, an international auditable certification standard that signals that a company goes beyond 
compliance standards to tailor to the well-being of its employees. According to Hofstede cultural dimensions and to GLOBE, Italy is an individualist and masculine (also called low humane orientation in GLOBE) culture. Past research has showed that, when operating in such a cultural setting, internal CSR should have a weak or even an insignificant effect on employees' behavioral responses (Farooq et al., 2014; Hofman \& Newman, 2014; Mueller et al., 2012; Newman et al., 2014). However, our results indicate that when a company obtains an internal CSR quality credential, particularly ISA8000, internal CSR initiatives will lead to positive employee behavioral outcomes, even when operating in a highly individualistic and masculine culture such as Italy. Our integrative model lends support to the positive and strong relationship between internal CSR initiatives and employees OCB, which is fully mediated by organizational identification and affective commitment. We probe this effect on OCB given that it is an important variable in the growing CSR micro mechanisms research (Farooq et al., 2016; Shen \& Benson, 2016) that can promote an organization's overall welfare, success and performance (Podsakoff et al., 1990; 2000).

In so doing, we make three contributions to the CSR literature. First, we present novel insights into factors shaping the micro-foundations of CSR in a company widely recognized for its social responsibility but that operates in a cultural context characterized by high individualism and masculinity. In this way, we contribute to the scant multilevel research on CSR (Gond et al., 2017; Shen \& Benson, 2016) by examining how the combination of macro cultural forces and mesoorganizational attributes affect micro individual outcomes. Second, by using bootstrapped mediated analysis (Hayes, 2013), we empirically validate the behavioral process through which internal CSR influences employees' OCB. We offer methodological contributions as bootstrapping allows to overcome assumptions of normality and allows the estimation of indirect and interaction effects simultaneously, therefore increasing the predictive validity of the model, an aspect that extant research is currently lacking. Third, we offer managerial guidance by suggesting that companies that obtain a certificate of excellence should consider internal CSR initiatives as an investment rather than a liability, even when operating in individualist and masculine cultures, given that this certificate will 
likely attract like-minded employees who will highly expect and positively react to internal CSR practices.

\section{Conceptual Background}

\section{Internal CSR, Collectivism and Masculinity}

Internal CSR, also called CSR to employees, reflects perceptions about a company's responsible behavior vis-à-vis employees, as, for example, the care exhibited to their careers, their needs, and their education (Bouraoui et al., 2018; Jamali et al., 2008; Turker, 2009). CSR to employees entails progressive Human Resource Management (HRM) practices that cater to the career growth and advancement of employees, and attend to their various needs (Bouraoui et al., 2018; Samara \& Arenas, 2017). Building on Turker's (2009) internal CSR dimension, scholars report mixed findings on how internal CSR initiatives will affect the behavioral outcomes of employees. For example, some research reports positive associations between CSR to employees and their respective behavioral outcomes (Farooq et al., 2014; Hofman \& Newman, 2014; Kim et al., 2016), while other research reports no significant relationship between perceptions of internal CSR and employees behavior and job related outcomes (Newman et al., 2014). Particularly, research has emphasized that the positive effects of internal CSR on the behavioral outcomes of employees is more likely to hold in cultures characterized by collectivism and femininity as opposed to individualist and masculine cultures (Farooq et al., 2014; Hofman \& Newman, 2014; Mueller et al., 2012).

Collectivism is defined as the degree to which people prioritize the well-being of their in-group over their self-interest. Individualism, however, suggests that people are opportunistic and are primarily concerned with their self-interest (Farh et al., 2004; Hofman \& Newman, 2014; Hofstede, 2001; Mueller et al., 2012; Samara \& Berbegal-Mirabent, 2018; Samara et al., 2019). For this reason, it has been suggested that collectivists are more likely to care about internal CSR initiatives and will therefore react positively to internal CSR practices, while individualist employees will not expect their companies to tailor to their well-being and will therefore neither expect nor reciprocate internal 
CSR initiatives with positive behavioral responses (Farooq et al., 2014; Hofman \& Newman, 2014; Mueller et al., 2012).

Masculinity is defined as the degree to which people value individual success and personal achievement as opposed to quality of life and social relationships (Hofstede, 2001; Hofman \& Newman, 2014). Furthermore, masculine cultures are described to be less compassionate and more focused on aggressiveness and materialistic gains than feminine cultures. Based on the latter, it has been suggested that in masculine cultures people are less likely to react positively to internal CSR initiatives and that this relationship is more likely to hold in cultures characterized by high femininity where people are ethically sensitive and expect more compassion (Hofman \& Newman, 2014).

At the same time, there is strong evidence to suggest a great degree of overlap between cultural dimensions and personality traits (Triandis, 2001). In other words, we might encounter people who have an individualist and masculine personality in collectivist and feminine cultures and people who have a collectivist and feminine traits in individualist and masculine cultures. Indeed, there is considerable support for the notion that individualism and masculinity can be measured and conceptualized as individual differences rather than merely differences at the macro cultural level (Robert \& Wasti, 2012; Triandis, 2001). In what follows, we argue that the company's specific attributes can provide signals as to what type of employees it will attract and how its internal stakeholders will expect to be treated

\section{Signaling Theory}

According to signaling theory (Spence, 1973), one party, the sender, aims to communicate a certain information (i.e. the signal) to the other party, the receiver, who evaluates and interprets the signal (Connelly et al., 2011; Spence, 1973). The value of signaling theory lies in ascribing value to how individuals and organizations get hold of significant information that results in an informed decision being made (Spence, 2002). Our main argument in this paper is that when an organization obtains a certificate of excellence, such as SA8000, the company sends a signal to prospective employees that it goes beyond legal norms to attend the needs and well-being of its employees. Subsequently, the 
company will likely attract like-minded individuals whose personality traits tend to be more collectivist and feminine even when operating in an individualist and masculine culture. Subsequently, employees will expect to be well-treated and will reciprocate their companies' internal CSR initiatives with positive behavioral responses.

\section{Hypotheses Development CSR and $\mathrm{OI}$}

OI is defined as "the degree to which a member defines him or herself by the same attributes that he or she believes define the organization" (Dutton et al., 1994, p. 239; see also Riketta, 2005). Hence, OI represents a significant psychological bond that companies have to manage for enhancing mutually supportive and symbiotic relationships between employees and their organizations (De Roeck and Delobbe, 2012; Kim et al., 2010).

When companies engage in activities that promote the welfare of their employees, this can create a sense of oneness with the company and its employees, as workers are likely to feel not only proud but also as an integrated, valued and congruent part of the organization in question (Peterson, 2004; Riketta, 2005). Similarly, when justice principles that promote merit are an integral part of CSR to employees, they in turn become central and enduring attributes of the organization HRM practices (Dutton et al., 1994; Parada et al., 2019). Based on signaling theory, individuals working in a company that has obtained an SA8000 certification will expect to be well-treated and will identify by their companies internal CSR practices. Therefore, the following hypothesis is proposed:

Hypothesis 1: CSR to employees positively influences employees' OI.

\section{CSR to Employees and Affective Commitment}

Allen and Meyer (1990, p.2) define AC as "affective or emotional attachment to the organization such that the strongly committed individual identifies with, is involved in, and enjoys membership in the organization." Accordingly, CSR to employees, through practices that contribute to employees training and development and to their health and emotional well-being, can engender feelings of emotional attachment to the organization. In addition, CSR to employees can ignite a desire of 
reciprocity, such as employees who were attracted by the signal of SA8000 will desire to reciprocate the care they receive from the organization by higher commitment to the company (Bouraoui et al., 2018). In other words, when the expectation of employees to be well-treated and be provided opportunities to learn and grow are fulfilled, they will form an emotional attachment to the organization. Based on the latter, we advance the following hypothesis:

Hypothesis 2: CSR to employees positively influences employees' AC.

\section{CSR to Employees and $O C B$}

OCB is grounded in the organizational behavior literature, which traditionally defines it as an extrarole behavior that enhances an organization's performance (Podsakoff and MacKenzie, 1994). OCB has received scarce attention in the CSR literature, except for a few studies (Gao and He, 2017; Newman et al., 2014; Rupp et al., 2006), where a positive association between employees' perception of CSR and OCB was found.

OCB has a discretionary nature that reveals an employee's positive reciprocal attitude toward an ethical behavior within the organization (Organ, 1988; Ryan, 2001). Accordingly, internal CSR practices that promote fairness and that reward teamwork, collaboration and mutual support will decrease competition among employees and will increase helping behavior among coworkers. Similarly, setting up procedures that contribute to the development of employees training and education and that support employees educational ambitions are likely to make employees more participant and vigilant of the company's peripheral activities, therefore increasing their civic virtue and sportsmanship which are considered as essential elements composing OCB (Newman et al., 2014; Rupp et al., 2006). Based on the latter we suggest:

Hypothesis 3: CSR to employees positively influences employees OCB.

\section{Organizational Identification, Affective Commitment, and $\mathrm{OCB}$}

Although Allen and Meyer's (1990) definition of AC is similar to Peterson's (2004) definition of OI

- "the relative strength of an individual's identification with and involvement in a particular organization" (p. 299) - these concepts are different in that "the self and the organization are 
perceived as one entity in terms of identification, but they remain independent entities in terms of commitment" (Kim et al., 2010, p.560). In other words, an individual may identify with an organization, without necessarily becoming committed to it, thus highlighting the importance of differentiating between these two concepts.

At the same time, the pertinent literature found that employee identification influences their state of mind by letting them become psychologically attached to and more committed to the company (Brammer et al., 2007; De Roeck and Delobbe, 2012; Jones et al., 2014). Based on the latter, we suggest that CSR to employees can influence AC not only in a direct way but also in an indirect way. CSR to employees primarily induces a positive identification at the cognitive level (Dutton et al., 1994; Peterson, 2004; Kim et al., 2010; Riketta, 2005), which, at a second stage, further increases employees AC to the organization (Allen and Meyer, 1990; Bouraoui et al., 2018). In the same manner, AC contributes to increase OCB. Indeed, employees who are affectively committed to the organization are more likely to create an environment where helping behavior, civic virtue and sportsmanship prosper (Gao and He, 2017). For these reasons, we hypothesize the following:

Hypothesis 4: OI positively influences employees AC;

Hypothesis 5: OI positively influences employees OCB;

Hypothesis 6: AC positively influences employees OCB.

\section{Method}

\section{Sample and procedure}

The sampling frame consisted of employees of one of the most important and largest Italian retail stores active in the food industry, which we name Alfa ${ }^{1}$. Alfa, operating in Italy, is a well-known example of a company that increasingly invests in CSR activities and was among the first to obtain SA8000 certification.. Hence, Alfa represents an ideal context to assess the interplay between meso-

\footnotetext{
${ }^{1}$ The name of the company has been changed to ensure anonymity.
} 
organizational attributes and the macro cultural setting affecting the relationship between internal CSR practices and employees behavioral responses.

A ten-page questionnaire comprising 35 items was developed in early 2016. Initially, the questionnaire was tested by a university student panel made up of ten graduate students who were not included in the final sample, to check for clarity of vocabulary, facility of completion, and possible ambiguity. After the pilot study, no substantive change was made to the final questionnaire. Through the direct collaboration of Presidents and Directors, the questionnaire was mailed to Alfa's employees from March 2016 to August 2016 to 15 Italian retail stores. Data collection yielded 309 questionnaires, indicating a response rate of $61.8 \%$ and after discarding incomplete surveys a usable sample of 300 questionnaires was utilized in this research. Non-response bias was assessed by conducting wave analysis through a comparison of early and late respondents. The results of $T$-tests across many variables - such as age, education, and other variables included in the study - showed no significant differences between the groups, thus confirming that non-response bias was not a threat of our study. To limit the threat of social desirability, participation was voluntary, anonymous, and no compensation was provided. Furthermore, we followed Podsakoff et al.'s (2003) guidelines, by separating the questions in the survey related to the independent/exogenous variable - namely CSR to employees - from those relating to the dependent/endogenous variables - such as employees' OCB.

\section{Measures}

Scales used in previous research were employed to measure the constructs analyzed in this study. We used a 7-point Likert-type scale ( $1=$ 'strongly disagree' to $7=$ 'strongly agree') to measure our constructs.

CSR to Employees was assessed using the widely cited instrument of Turker (2009), a validated CSR four-factor scale focused on employees' perceptions related to different types of stakeholders. Turker's instrument defines four dimensions indicating a company's CSR, namely CSR to (a) society/environment/future generations, (b) employees, (c) customers, and (d) government. Such a 
scale has been recently used for assessing employees' perception of an organization's CSR toward different types of stakeholders (De Roeck and Delobbe, 2012). Since the aim of this study is to assess the level of a company's CSR activities toward employees, we use the second dimension of this instrument, which is focused on CSR toward employees. The scale is composed of five items and Turker (2009) obtained a scale reliability estimate of $\alpha=0.88$.

Organizational identification (OI) was measured with the scale developed by Mael and Ashforth (1995), which is widely used in the CSR literature (see De Roeck and Delobbe, 2012; Dutton et al., 1994; Kim et al., 2010). OI refers to "a specific form of social identification in which people define themselves in terms of their membership in a particular organization" (Mael and Ashforth, 1995, p. 311-312; see also Ashforth and Mael, 1989). The scale is composed of five items and Mael and Ashforth obtained a scale reliability estimate of $0.74(\alpha)$.

Affective Commitment was assessed with the four items developed by Meyer and colleagues designed to measure employees' emotional attachment to and involvement in the organization (Meyer and Herscovitch, 2001; Meyer et al., 1993). The authors validated a three-dimensional instrument for assessing organizational commitment, considering also continuance and normative aspects. However, Affective Commitment represents the dimension that has been predominantly used in the organizational behavior and CSR literature (Brammer et al., 2007; De Roeck and Delobbe, 2012; Kim et al., 2010). Meyer et al. (1993) obtained a scale reliability estimate of $\alpha=0.86$.

The employees' level of $O C B$ was assessed using the three-dimensional OCB instrument developed by Podsakoff and MacKenzie (1994). This OCB measurement builds on Organ's (1988) original dimensions, namely altruism, courtesy, conscientiousness, civic virtue, and sportsmanship. In the present research, we build on Ryan (2001) and interpret $O C B$ as a global construct encompassing three sub-scales, namely (a) Civic Virtue which refers to "Behavior on the part of the individual that indicates that he/she responsibly participates in, is involved in, or is concerned about the life of the organization" (Ryan, 2001, p. 234). This sub-scale is composed of four items and Ryan (2001) obtained a scale reliability estimate of $\alpha=0.70$. (b) Helping Behavior refers to an employee's 
discretionary behavior aimed at helping his/her colleagues and preventing work-related problems (Podsakoff and MacKenzie, 1994). This sub-scale is composed of six items and Ryan (2001) obtained a scale reliability estimate of $\alpha=0.70$. (c) Sportsmanship is defined as the "Willingness of an employee to tolerate less than ideal circumstances without complaining" (Ryan, 2001, p. 234). This sub-scale is composed of four items and Ryan (2001) obtained a scale reliability estimate of $\alpha=0.78$.

\section{Analysis and Results}

Sample characteristic, scales and items' descriptive statistics

The majority of the respondents were female (76.0\%) and $24.3 \%$ were $31-45$ years of age; $58 \%$ respondents hold a high school degree and 41\% had 11-20 years of work experience. In Table 1 the scales and items' descriptive statistics are shown.

Insert Table 1 about here.

Mean scores of CSR to Employees items indicated that the respondents have a generally positive perception of Alfa's CSR initiatives. Mean scores of OI and Affective Commitment are high as well, thus indicating respondents' positive construed image of and behavioral attitude toward the company. The scales used in the research present good reliability, as shown in Table 1.

The results of the correlation analysis of scale items and validity of the model are illustrated in Table 2.

Insert Table 2 about here.

Interestingly, CSR to employees was significantly and strongly correlated with all the other variables of the model, with $r$ values ranging from 0.443 ( $p<0.01$; Helping Behavior) to 0.643 ( $p<0.01$; OI). For each of the model dimensions, a confirmatory factor analysis (CFA) was conducted using SPSS' module AMOS v. 22 (Hair et al., 2006). The maximum likelihood function of AMOS was used to 
estimate parameters and build a measurement model (Faraoni et al., 2019; Laudano et al., 2019; Zollo et al., 2017a). The goodness-of-fit measures were examined to verify acceptable parsimony of the analyzed model. First, absolute fit indexes were measured. The Chi-square statistics of the model is significant $\left(\chi^{2}=685.388 p<0.01\right)$ and the relative Chi-square suggests good fit with a T-test of $\chi^{2} /$ $\mathrm{df}=2.115$ (lower than 3 as required) (Bagozzi and Yi, 1988). The 'Goodness of Fit Index' (GFI) measures the fit between the hypothesized model and the covariance matrix of the observed variables, indicating a model fit for values approaching 0.90 (Bagozzi and Yi, 1988). GFI of the model (0.860) suggests acceptable fit. The last absolute fit index is the 'Root Mean Square Error of Approximation' (0.061) and suggests a good fit, being lower than 0.07 . A second category of indexes refers to the relative fit indexes. According to Bagozzi and Yi (1988), CFI, IFI, NFI, and TLI above 0.90 are satisfactory. The model indicates sufficient fit indexes $(\mathrm{CFI}=0.930 ; \mathrm{IFI}=0.931 ; \mathrm{NFI}=0.880$; TLI $=0.919)$.

The measurement model shows that all the factor loadings are significant $(p<0.01)$. To assess the internal consistency of the indicators, the Composite Reliability (CR) for each latent construct was estimated (Hair et al., 2006). According to Bagozzi and Yi (1988), CR values higher than 0.6 are required. As Table 2 shows, our variables CSR to Employees (0.850), OI (0.893), Affective Commitment (0.907), and OCB (0.853) show acceptable CR of the model. Convergent validity was assessed by the 'Average of Variance Extracted' (AVE). According to Bagozzi and Yi (1988), AVE values higher than 0.5 indicate good convergent validity. All the constructs show acceptable values, namely CSR to Employees (0.660), OI (0.697), Affective Commitment (0.781), and OCB (0.777). Moreover, to assess the model discriminant validity, the square root of the constructs' AVEs has to be greater than the correlations among constructs of the model (Hair et al., 2006). The square roots of all constructs' AVEs are greater than the correlations values, thus indicating acceptable discriminant validity.

A common concern of self-reported questionnaires refers to the possibility of common method bias (CMB) distorting the hypothesized relationships when all variables are collected from the same 
source during the same period of time (Podsakoff et al., 2003). Hence, we followed the procedures suggested by Podsakoff et al. (2003) and (a) pre-tested the scales in order to delete ambiguous items from the questionnaire; (b) conducted the Harman's one-factor test, which failed to identify a general factor that accounted for the majority of the total variance (equal to 19.50\%); (c) used CFA to compare our proposed model with a model loading all items onto a common method factor: the "onefactor model" (Podsakoff et al., 2003). The comparison showed a significant change in chi-square as requested: the $\chi 2$ difference test with one degree of freedom was greater than 3.84 , which is the critical value associated with a $p$-value of 0.05 - thus assessing a better fit to the data of our hypothesized model in respect to the one-factor model (Zollo et al., 2018). Therefore, CMB does not represent a significant threat in our study.

\section{Hypotheses testing}

To test the proposed mediational hypotheses, we followed the procedures proposed by Hayes (2013) using SPSS PROCESS macro (v. 2.16). Particularly, we conducted a multistep mediator analysis (model 6 of PROCESS with 2 mediators) through the bootstrapping method, one of the most popular techniques to test the extent and significance of mediational effects (Rialti et al., 2019; Zollo et al., 2017b). We computed 5000 bootstrap samples and 95\% bias-corrected lower levels confidence intervals (LLCIs) and upper levels confidence intervals (ULCIs) around the estimates of indirect effects.

Following Hayes's (2013) approach (Figure 1), CSR to Employees, the independent variable, should be significantly related to $\mathrm{OI}$ and $\mathrm{AC}$, the mediation variables. Next, mediation variables should be significantly related to one another; specifically, OI should significantly impact on AC. After controlling for the effect of independent variables, mediation variables should be significantly related to OCB, the dependent variable (Zollo et al., 2019). Mediation is indicated by the significance level of the indirect effect from CSR to Employees to OCB through OI and AC, as indicated by the $p$-value or the LLCIs and ULCIs. In other words, CSR to Employees should 
have a different total rather than direct effect on OCB, thus yielding an indirect effect different from zero. As Figure 1 shows:

Insert Figure 1 about here.

As shown in Figure 1, CSR to Employees was positively related to OI $(+0.48 ; p<0.01)$ and AC $(+0.71 ; p<0.01)$, providing statistical support for $H 1$ and $H 2$, respectively. Moreover, CSR to Employees significantly predicted employees' OCB $(+0.54 ; p<0.01)$, thus supporting $H 3$. Next, OI was strongly related to AC $(+0.78 ; p<0.01)$, supporting $H 4$. Similarly, both OI $(+0.82 ; p<$ $0.01)$ and $\mathrm{AC}(+0.60 ; p<0.01)$ were significantly and highly related to $\mathrm{OCB}$, thus providing empirical support for $H 5$ and $H 6$, respectively. Finally, concerning the relationship between CSR to Employees and OCB, the original total effect $(+0.54 ; p<0.01)$ significantly differed from the direct effect that was non significant $(p>0.05)$ due to the influence of the two mediators, namely OI and AC (Hayes, 2013). Hence, both OI and AC were total mediators of the relationship, providing statistical support for H6. In other words, the relationship between CSR to employees and OCB is "fully" explained by the mediating variables, which actually represents the underlying mechanisms explaining employees' perceptions of a company's CSR initiatives and their citizenship behavior.

\section{Discussion}

Do employees really care less about internal CSR initiatives when operating in an individualist and masculine culture? Our findings, based on a robust methodology, strongly suggest the opposite effect. While prior research has showed that internal CSR initiatives may not have a strong effect and may even have an insignificant effect on employees behavioral outcomes in individualist and masculine cultures (Farooq et al., 2014; Hofman \& Newman, 2014; Mueller et al., 2012; Newman et al., 2014), our multilevel approach suggests that this is not necessarily true and that firm and industry specific attributes need to carefully be considered to truly understand this relationship. Particularly, our 
findings show that CSR to employees can reinforce employees' organizational identification and affective commitment, which further reinforce their OCB. Hence, our results confirm the premise suggesting that an organization that has obtained an internal CSR certificate of excellence will attract employees that have collectivist and feminine personality traits and that these employees will expect to be well treated. Subsequently, satisfying employees' cognitive and emotive expectations (Samara et al., 2019) will likely lead them to have a positive identification with the company, which enhances their affective commitment, all of which contribute to their OCB.

\section{Theoretical implications}

The present research contributes to recent calls for multilevel research to truly understand the effect of a company's socially responsible activities on its employees behavioral outcomes (De Roeck and Delobbe, 2012; Gond et al., 2017; Lin, 2010; Samara et al., 2019). To date, the main gist of prior research is that the positive behavioral responses of employees to their companies CSR engagement is weak or even insignificant in individualist and masculine cultures (Farooq et al., 2014; Hofman \& Newman, 2014; Mueller et al., 2012; Newman et al., 2014). In such cultures, it has been argued that employees will not care about a firm's commitment to social issues and that firms will not be expected to contribute to their employees' welfare. Our research, however, shows that this paints an incomplete picture of employees behavioral responses to internal CSR initiatives and that companies specific attributes need to be taken carefully into consideration to better explain the interlinkages between cultural context, companies internal CSR initiatives and employees behavioral responses. Drawing on signaling theory, this research shows that employees are sensitive to the signals and orientations that emanate from how the company describes its internal CSR practices. Hence, we suggest that future research should examine the relationship between internal CSR initiatives and employees behavioral responses from a multilevel approach to increase extant knowledge on how, when, and how internal CSR can affects various employees' behavioral outcomes.

\section{Managerial Implications}


The present study also provides significant implications for managers. Given our results, it is important that managers invest in internal stakeholders' - especially employees' - positive perceptions of CSR in order to enhance the overall organizational climate. Hence, more attention needs to be directed toward HR processes, such as recruitment and work rewards (Samara \& Paul, 2019; Samara et al., 2019), in order to foster a stronger sense of identification and commitment among employees (Parada et al., 2019). Our results also demonstrate that in the Italian food industry sector the ethical orientation of the firm influences employees' identification with their company. These results cannot be completely disentangled from the combination of company specific attributes and cultural factors that influence people's self-concept and self-construal (Cross et al., 2000; Kim et al., 2010). This reveals that when employees expect to be well-treated they will refer to the notion of 'relational self-construal', which embodies both "the individual's desire of reciprocity and expectations of equity in close relationships" and "thinking of oneself in terms of close others or identifying with close others" (Cross et al., 2000, p. 793). Actually, OCB is a discretionary extra-role performance (Organ, 1988; Ryan, 2001) which invokes employees' relational self-concept due to elements such as helping behavior, sportsmanship, and civic virtue.

To summarize, our findings reveal that investments in CSR emerge as a strategic lever whenever a company seeks to improve its employee identification, commitment, and OCB. Our nuanced findings suggest the importance of meeting the expectations of employees to be well treated when a company frames itself as internally responsible through obtaining a certificate of excellence, even when operating in an individualist and masculine culture.

\section{Limitations and directions for future research}

Although this study makes an important contribution by validating the behavioral process through which CSR to employees increase OCB, it also has some limitations that can open several interesting avenues for additional research. First, we conducted our study in the Italian context that although scarcely investigated, represents a single individualist and masculine country, which can threaten the external validity of our results. Hence, our proposed model should be tested, for example, in other 
countries showing similar cultural traits. Relatedly, it would be interesting to see if the proposed relationships would yield the same results in collectivist and feminine cultures and in industries characterized by high aggressiveness and competition. As recently stressed by pertinent literature (Kim et al., 2010), cross-cultural studies incorporating individual and national culture features, as possible moderators of the linkages between CSR and employees' behavior, are likely to be useful in further advancing knowledge in this important field.

Second, we consider only OI, affective commitment, and OCB as employees' behavioral and cognitive responses to CSR initiatives. Particularly referring to the OCB construct, it would be interesting to investigate antecedents and outcomes of the dimensions referring to both the OCBI (organizational citizenship behavior to individuals) - such as altruism and courtesy - and dimensions referring to the OCBO (organizational citizenship behavior to the organization) - such as conscientiousness, civic virtue and sportsmanship - in order to better conceptualize this construct in the CSR context. Finally, our study has focused on a single company operating in a particular industry, namely the retail sector. We propose to test our model in other industries, such as finance, services, and business-to-business, thus investigating possible differences in employees' CSR responses. Particularly, since our findings result from employees working in one of the largest and important Italian companies, we encourage future researchers to assess our propositions in other organizational contexts (e.g., SMEs that have obtained SA8000 certification and those that have not obtained any certification) in order to further test the robustness of the findings presented, and the overall insights derived through this research.

\section{References}

Allen, N.J., \& Meyer, J.P. (1990). The Measurement and Antecedents of Affective, Continuance, and Normative Commitment to the Organization. Journal of Occupational Psychology, 63(1), 1-18.

Ashforth, B.E., \& Mael, F. (1989). Social identity theory and the organization. Academy of Management Review, 14(1), 20-39. 
Bagozzi, R.P., \& Yi, Y. (1988). On the evaluation of structural equation models. Journal of the Academy of Marketing Science, 16(1), 74-94.

Bouraoui, K., Bensemmane, S., Ohana, M., \& Russo, M. (2018). Corporate social responsibility and employees' affective commitment: A multiple mediation model. Management Decision. DOI: 10.1108/MD-10-2017-1015.

Brammer, S., Millington, A. \& Rayton, B. (2007). The Contribution of Corporate Social Responsibility to Organizational Commitment. International Journal of Human Resource Management 18(10), 1701-1719.

Connelly, B. L., Certo, S. T., Ireland, R. D., \& Reutzel, C. R. (2011). Signaling theory: A review and assessment. Journal of Management, 37(1), 39-67.

Cross, S.E., Bacon, P.L., \& Morris, M.L. (2000). The relational-interdependent self-construal and relationships. Journal of Personality and Social Psychology, 78(4), 791-808.

De Roeck, K., \& Delobbe, N. (2012). Do environmental CSR initiatives serve organizations' legitimacy in the oil industry? Exploring employees' reactions through organizational identification theory. Journal of Business Ethics, 110(4), 397-412.

Dutton, J. E., Dukerich, J. M., \& Harquail, C. V. (1994). Organizational images and member identification. Administrative Science Quarterly, 39(2) 239-263.

Edinger-Schons, L. M., Lengler-Graiff, L., Scheidler, S., \& Wieseke, J. (2019). Frontline employees as corporate social responsibility (CSR) ambassadors: A quasi-field experiment. Journal of Business Ethics, 157(2), 359-373.

Faraoni, M., Rialti, R., Zollo, L., Pellicelli A.C. (2019). Exploring e-Loyalty Antecedents in B2C eCommerce: Empirical Results from Italian Grocery Retailers. British Food Journal, 121(2), 574-589.

Farh, J. L., Zhong, C. B., \& Organ, D. W. (2004). Organizational citizenship behavior in the People's Republic of China. Organization Science, 15(2), 241-253.

Farooq, O., Payaud, M., Merunka, D., \& Valette-Florence, P. (2014). The impact of corporate social responsibility on organizational commitment: Exploring multiple mediation mechanisms. Journal of Business Ethics, 125(4), 563-580.

Farooq, M., Farooq, O., \& Jasimuddin, S. M. (2014). Employees response to corporate social responsibility: Exploring the role of employees' collectivist orientation. European Management Journal, 32(6), 916-927.

Farooq, O., Rupp, D. E., \& Farooq, M. (2017). The multiple pathways through which internal and external corporate social responsibility influence organizational identification and multifoci outcomes: The moderating role of cultural and social orientations. Academy of Management Journal, 60(3), 954-985.

Gao, Y., \& He, W. (2017). Corporate social responsibility and employee organizational citizenship behavior: the pivotal roles of ethical leadership and organizational justice. Management Decision, 55(2), 294-309. 
Gond, J. P., El Akremi, A., Swaen, V., \& Babu, N. (2017). The psychological microfoundations of corporate social responsibility: A person-centric systematic review. Journal of Organizational Behavior, 38(2), 225-246.

Hair, J.F., Black, W.C., Babin, B.J., Anderson, R. E., \& Tatham, R. L. (2006). Multivariate data analysis (Vol. 6). New York, NJ: Pearson Prentice Hall.

Hayes, A.F. (2013). Introduction to Mediation, Moderation, and Conditional Process Analysis: A Regression-Based Approach. New York, NY: Guilford Press.

Hofman, P. S., \& Newman, A. (2014). The impact of perceived corporate social responsibility on organizational commitment and the moderating role of collectivism and masculinity: Evidence from China. The International Journal of Human Resource Management, 25(5), 631-652.

Hofstede, G. (2001). Culture's consequences: Comparing values, behaviors, institutions and organizations across nations. Sage publications.

Jamali, D., Safieddine, A., \& Rabbath, M. (2008). CG and CSR: Synergies and inter-relationships. Corporate Governance: An International Review, 16(5), 443-459.

Jamali, D., Samara, G., \& Hossary, M. (2019). 12 Corporate social responsibility and development. Business and Development Studies: Issues and Perspectives. Routledge.

Jones, D. A., Willness, C. R., \& Madey, S. (2014). Why are job seekers attracted by corporate social performance? Experimental and field tests of three signal-based mechanisms. Academy of Management Journal, 57(2), 383-404.

Kim, H.R., Lee, M., Lee, H.T., \& Kim, N. M. (2010). Corporate social responsibility and employeecompany identification. Journal of Business Ethics, 95(4), 557-569.

Kim, J. S., Song, H. J., \& Lee, C. K. (2016). Effects of corporate social responsibility and internal marketing on organizational commitment and turnover intentions. International Journal of Hospitality Management, 55, 25-32.

Laudano, M. C., Zollo, L., Ciappei, C., \& Zampi, V. (2019). Entrepreneurial universities and women entrepreneurship: a cross-cultural study. Management Decision, 57(9), 2541-2554.

Mael, F.A., \& Ashforth, B.E. (1995). Loyal from day one: Biodata, organizational identification, and turnover among newcomers. Personnel Psychology, 48(2), 309-333.

Meyer, J.P., Allen, N.J., \& Smith, C.A. (1993). Commitment to Organizations and Occupations: Extension and Test of a Three-Component Conceptualization. Journal of Applied Psychology, 78(4), 538-551.

Meyer, J. P., \& Herscovitch, L. (2001). Commitment in the workplace: Toward a general model. Human Resource Management Review, 11(3), 299-326.

Mueller, K., Hattrup, K., Spiess, S. O., \& Lin-Hi, N. (2012). The effects of corporate social responsibility on employees' affective commitment: A cross-cultural investigation. Journal of Applied Psychology, 97(6), 1186. 
Newman, A., Kiazad, K., Miao, Q., \& Cooper, B. (2014). Examining the cognitive and affective trustbased mechanisms underlying the relationship between ethical leadership and organisational citizenship: A case of the head leading the heart? Journal of Business Ethics, 123(1), 113-123.

Organ, D.W. (1988). Organizational citizenship behavior: The good soldier syndrome. Lexington, MA: Lexington Books.

Parada, M. J., Samara, G., Dawson, A., \& Bonet, E. (2019). Prosperity over time and across generations: the role of values and virtues in family businesses. Journal of Organizational Change Management (forthcoming).

Peterson, D.K. (2004). The Relationship Between Perceptions of Corporate Citizenship and Organizational Commitment. Business \& Society, 43(3), 296-319.

Podsakoff, P. M., MacKenzie, S. B., Moorman, R. H., \& Fetter, R. (1990). Transformational leader behaviors and their effects on followers' trust in leader, satisfaction, and organizational citizenship behaviors. The Leadership Quarterly, 1(2), 107-142.

Podsakoff, P.M., \& MacKenzie, S.B. (1994). Organizational citizenship behaviors and sales unit effectiveness. Journal of Marketing Research, 31(3), 351-363.

Podsakoff, P. M., MacKenzie, S. B., Paine, J. B., \& Bachrach, D. G. (2000). Organizational citizenship behaviors: A critical review of the theoretical and empirical literature and suggestions for future research. Journal of Management, 26(3), 513-563.

Podsakoff, P.M., MacKenzie, S.B., Lee, J.Y., \& Podsakoff, N.P. (2003). Common method biases in behavioral research: a critical review of the literature and recommended remedies. Journal of Applied Psychology, 88(5), 879-903.

Rialti, R., Zollo, L., Ferraris, A., Alon, I. (2019). Big data analytics capabilities and performance: Evidence from a moderated multi-mediation model. Technological Forecasting \& Social Change, Vol.149. DOI: 10.1016/j.techfore.2019.119781

Riketta, M. (2005). Organizational identification: A meta-analysis. Journal of Vocational Behavior, 66(2), 358-384.

Robert, C., \& Wasti, S. A. (2002). Organizational individualism and collectivism: Theoretical development and an empirical test of a measure. Journal of Management, 28(4), 544-566.

Rupp, D.E., Ganapathi, J., Aguilera, R.V., \& Williams, C.A. (2006). Employee Reactions to Corporate Social Responsibility: An Organizational Justice Framework. Journal of Organizational Behavior, 27(4), 537-543.

Ryan, J.J. (2001). Moral reasoning as a determinant of organizational citizenship behaviors: A study in the public accounting profession. Journal of Business Ethics 33(3), 233-244.

Samara, G., \& Arenas, D. (2017). Practicing fairness in the family business workplace. Business Horizons, 60(5), 647-655. 
Samara, G., \& Berbegal-Mirabent, J. (2018). Independent directors and family firm performance: does one size fit all?. International Entrepreneurship and Management Journal, 14(1), 149-172.

Samara, G., \& Paul, K. (2019). Justice versus fairness in the family business workplace: A socioemotional wealth approach. Business Ethics: A European Review, 28(2), 175-184.

Samara, G., Jamali, D., \& Parada, M. J. (2019). Antecedents and outcomes of bifurcated compensation in family firms: A multilevel view. Human Resource Management Review (forthcoming).

Shen, J., \& Benson, J. (2016). When CSR is a social norm: How socially responsible human resource management affects employee work behavior. Journal of Management, 42(6), 1723-1746.

Spence, M. (1973). Job market signaling. Quarterly Journal of Economics, 87(3), 355-374.

Spence, M. (2002). Signaling in retrospect and the informational structure of markets. American Economic Review, 92(3), 434-459.

Triandis, H. C. 2001. Individualism-collectivism and personality. Journal of Personality, 69(6), 907924.

Turker, D. (2009). Measuring corporate social responsibility: A scale development study. Journal of Business Ethics 85(4), 411-427.

Wang, J., Zhang, Z., \& Jia, M. (2019). Echoes of Corporate Social Responsibility: How and When Does CSR Influence Employees' Promotive and Prohibitive Voices?. Journal of Business Ethics, 1-17. DOI: 10.1007/s10551-019-04151-6.

Zollo, L., Faldetta, G., Pellegrini, M. M., \& Ciappei, C. (2017a). Reciprocity and gift-giving logic in NPOs. Journal of Managerial Psychology 32(7), 513-526.

Zollo, L., Laudano, M. C., Boccardi, A., \& Ciappei, C. (2019). From governance to organizational effectiveness: the role of organizational identity and volunteers' commitment. Journal of Management and Governance 23(1), 111-137.

Zollo, L., Laudano, M. C., Ciappei, C., \& Zampi, V. (2017b). Factors affecting universities' ability to foster students' entrepreneurial behaviour: An empirical investigation. Journal of Management Development 36(2), 268-285.

Zollo, L., Yoon, S., Rialti, R., \& Ciappei, C. (2018). Ethical consumption and consumers' decision making: the role of moral intuition. Management Decision 56(3), 692-710. 